\title{
Interoperabilidad y publicidad a través del registro mercantil electrónico
}

Interoperability and publicity through the electronic commercial registry

\author{
María José Vaño Vaño \\ Universitat de Valencia (España) \\ mjvanyo@uv.es
}

\begin{abstract}
Resumen
El Registro mercantil está desarrollando la interoperabilidad registral. Permite la actualización en línea con el uso de XML. Se están integrando en una plataforma a nivel europeo de interconexión registral. La publicidad formal del registro mercantil se modifica sustancialmente al complementarse con la publicidad a través de la web corporativa. Se equipara la web al domicilio social a efectos de publicidad y ejercicio de los derechos de información de los socios.
\end{abstract}

Palabras clave: XML. Publicidad formal. Registro mercantil. Interoperabilidad. Domicilio social electrónico. Registro mercantil europeo.

\section{Aspectos generales y funciones}

Las funciones del Registro Mercantil, oponibilidad y publicidad (artículo 12 del Reglamento del Registro Mercantil) impuestas por las Directivas comunitarias, ha sufrido una importante modificación en la normativa reguladora de las sociedades de capital que buscan la agilización y el uso en la gestión de las tecnologías de la información y comunicación.

La equiparación de la web al domicilio social y el uso de la web a efectos de publicidad, vinculada al principio de publicidad registral, ofrecen un marco perfecto para el desarrollo de las tecnologías de la información en el marco societario.

De hecho, las funciones del Registro Mercantil Central, con la centralización de las denominaciones, ordenación, tratamiento y publicidad de la información de los actos relativos a los actos sociales inscritos en los Registros mercantiles territoriales, o la publicidad en el Boletín Oficial del Registro Mercantil, se articula a través de las tecnologías de la información y comunicación.

También los Registros mercantiles territoriales han desarrollado sus portales con el fin de que los empresarios puedan interactuar por vía telemática, desde la legalización de los libros de los empresarios, al nombramiento de expertos independientes, o el depósito y publicidad de

\begin{abstract}
The commercial registry is enhancing the registry interoperability. It supports on-line updating by XML. It is being integrated in a European Business Register Interoperability platform. Formal advertising of the commercial register has been substantially modified by being complemented with advertising throughout the corporate website. The website has the same value than the physical address of the registry for the purpose of advertising and exercising the partners' rights to information.
\end{abstract}

Keywords: Formal disclosure. Commercial registry. Interoperability. Electronic registries. European commercial registry.

documentos contables. Todo ello se modificó con la promulgación de numerosas disposiciones que reformularon el intercambio de datos en un primer momento en el seno de los Registros Mercantiles. Posteriormente se desarrolló la vertiente extra-registral tal y como impusieron las Directrices comunitarias a causa de las grandes diferencias existentes entre los diferentes Estados (Fernández del Pozo, 2003). Por ello ha sido necesario buscar la unificación de contenidos y de registro del mismo tipo de documentación, para favorecer la interoperabilidad.

\section{Publicidad a partir del Registro Mercantil}

El pilar básico sobre el que se asienta la publicidad del Registro Mercantil es la coordinación de las disposiciones nacionales relativas a la publicidad, de modo que los terceros puedan conocer los actos esenciales de la sociedad y ciertas indicaciones relativas a ella. Tradicionalmente se ha considerado que el Registro Mercantil es una institución que sirve a la seguridad del tráfico y procura la tutela de los intereses de los sujetos inscritos. Fundamentalmente tiende a tutelar la confianza en la apariencia, ordenación de los intereses en juego y las relaciones entre sociedad, terceros y socios (Farias Batlle, 1998; 
García Villaverde, 1990; Fernández Del Pozo, 1990).

La primera Directiva de Sociedades, 68/151/CE, calificó el Registro Mercantil de Público, pero con el fin de ofrecer una oponibilidad rigurosa de la información allí registrada, se creó un Boletín Oficial, de tal forma que la plenitud de efectos de la publicidad formar sólo se conseguiría tras la inscripción y posterior publicación en el mismo. Sin embargo fue objeto de crítica a causa de la celeridad del tráfico mercantil (Vicent Chuliá y Fernández del Pozo, 2000).

Posteriormente, el texto original se modificó por la Directiva 2003/58/CE, añadiendo la posibilidad de utilizar las tecnologías de la información y comunicación. A tales efectos, en el apartado 4 del art. 3, lo regula en los siguientes términos:

La publicidad de los actos y las indicaciones que se mencionan en el apartado 2 se realizará por medio de una publicación literal o en extracto, o bien bajo la forma de una mención en el boletín nacional designado por el Estado miembro que señale el depósito del documento en el expediente o su transcripción en el registro. El boletín nacional designado al efecto por el Estado miembro podrá estar en formato electrónico.

Los Estados miembros podrán optar por sustituir dicha publicación en el boletín nacional por otra medida de efecto equivalente que implique, como mínimo, la utilización de un sistema que permita consultar las informaciones publicadas en orden cronológico a través de una plataforma electrónica central.

En la práctica los distintos sistemas registrales han organizado su publicidad formal para que sea más accesible. Las copias de los asientos se facilitan vía Internet y también se pueden facilitar copias certificadas electrónicamente (Vicent Chuliá y Fernández del Pozo, 2000).

En cualquier caso, la Primera Directiva de Sociedades, añade, en el apartado 5 del citado art. 3 , que los actos e indicaciones no serán oponibles frente a terceros por la sociedad hasta después de la publicación mencionada en el apartado 4, excepto si se demuestra que estos terceros ya tenían conocimiento de los mismos (García Villaverde, 1990; Fernández del Pozo, 1990).

En la Primera Directiva de Sociedades, destaca y define el concepto por medios electrónicos, de manera que la información se envíe desde la fuente, y se reciba en su destino utilizando equipos electrónicos de tratamiento (incluida la compresión digital) y de almacenamiento de datos y que transmita, canalice y reciba enteramente por hilos, radio, medios ópticos o cual- quier otro medio electromagnético del modo establecido por los Estados miembros.

La publicidad por ordenador se regula en el art. 79 del Reglamento del Registro Mercantil, al señalar que

[l]os Registradores Mercantiles facilitarán a los interesados la consulta de los datos relativos al contenido esencial de los asientos por medio de terminales de ordenador instalados a tal efecto en la oficina del Registro.

El art. 382.1 contempla la expedición por el Registrador Mercantil de sus notas simples informativas a través de sistemas de telecomunicación informáticos.

En la Instrucción de la Dirección General de los Registros y del Notariado de 29 de octubre de 1996 se anticipó a regular la citada publicidad instrumental contenida en el Servicio de Índices del Colegio de Registradores. Incluso se contempló la interconexión entre Registradores Mercantiles y de la Propiedad para la solicitud y remisión de notas simples

La Orden de 10 de junio de 1997 impuso la obligación de intercomunicación entre los Registradores provinciales a efectos de la expedición de la publicidad formal por nota simple informativa.

La Instrucción de la DGRN de 10 de junio de 1999 recogió en el art. 8 la regulación relativa a la recuperación informática de los datos del archivo histórico estableciendo unos plazos determinados.

Ya el art. 332 del Reglamento Hipotecario, aplicable al Registro Mercantil por remisión del art. 80 del RRM, en su redacción de 1998, obligaba a la existencia de interconexión de todos los Registradores a través de una «red de telecomunicación».

La Resolución de la DGRN de 10 de abril de 2000 , ordenaba a todas las oficinas registrales que dispusieran de correo electrónico con el fin de formar una red telemática de información registral que permita la comunicación con cualquier usuario. Se creó un Fichero Localizador de Entidades Inscritas («FLEI») de tal forma que la consulta realizada se redirigía a través de la plataforma central hacia el Registro Mercantil competente dentro de la Intranet registral (Proyecto Aequitas).

Con la Resolución-Circular de 26 de abril de 2000 de la DGRN sobre la aplicación de la firma electrónica a la actuación profesional de los Registradores de la Propiedad y Mercantiles, se reguló la solicitud y expedición de certificaciones electrónicas. Fue la Instrucción de la DGRN de 
19 de octubre de 2000 la que reguló el uso de la firma electrónica por los fedatarios, obligando a los colegios de Notarios y Registradores a constituirse en prestadores de firma acreditados. En la Instrucción de 23 de octubre de 2001 se reguló la cláusula autorizatoria para la presentación telemática de contratos al Registro de Bienes Muebles.

Antes de que fueran incorporados por el Legislador los medios electrónicos a la inscripción y publicidad del lo inscrito en el Registro Mercantil, se calificaba este sistema como erróneo, aparatoso y antieconómico y algunos autores precisaban la necesidad de que fuera modificado inmediatamente (Vicent Chuliá y Fernández del Pozo, 2000). Se consideraba erróneo al seguir el anacronismo de la doble publicidad (inscripción en el Registro Mercantil y publicación en el BORME), impuesto por el art. 3 de la Primera Directiva. También se consideraba erróneo al apoyarse en la presunción poco realista de que los operadores del tráfico leen los anuncios publicados en la prensa y en el BORME y que consultan el Registro Mercantil antes de contratar. Y se consideraba aparatoso y costoso porque unas veces la publicación obligatoria de anuncios en prensa y en el Boletín Oficial del Registro Mercantil resultaba superflua y otras veces la publicidad es necesaria, a fin de posibilitar a los socios y terceros el ejercicio de sus derechos.

Todo ello ha venido a paliarse con la promulgación con la Ley de Sociedades de capital. También han contribuido a ello, las diferentes reformas de la misma, y en particular, la que ha supuesto un gran cambio en el modo de dar publicidad de los actos inscritos en el Registro Mercantil a través de la Ley $25 / 2011$, de 1 de agosto, de reforma parcial de la Ley de Sociedades de Capital y de incorporación de la Directiva 2007/36/CE, del Parlamento Europeo y del Consejo, de 11 de julio, sobre el ejercicio de determinados derechos de los accionistas de sociedades cotizadas. Permitiendo utilizar la web de la sociedad (arts. 11bis y 11ter LSC) como sustitutiva de los anuncios publicados en la prensa, siempre que previamente se haya comunicado al Registro Mercantil el acuerdo de creación de la página web, que según esta norma, será competencia de la Junta general. Sin embargo sus modificaciones se dejan en manos de los administradores.

\section{Inscripción en el Registro Mercantil}

La Directiva del Parlamento Europeo y del Consejo, 58/2003, por la que se modifica la Directiva 68/151/CEE del Consejo (Primera Directiva de sociedades) regula los requisitos de información con respecto a determinados tipos de empresas, sociedades de capital. De modo específico señala que cualquier sitio web de la sociedad contenga unos datos mínimos identificativos de la sociedad o la sustitución de la publicación en el Boletín Oficial del Registro por una web de los Registros mercantiles. Esta Directiva imponía numerosas obligaciones de aplicación a partir del 1 de enero de 2007 (Del Valle Hernández, 2008).

En particular, el art. 2 de modificación de la primera directiva de sociedades describe las medidas que deben adoptar los Estados miembros con el fin de que la publicidad obligatoria relativa a las sociedades permita a los terceros conocer los actos esenciales de la sociedad.

Según este precepto, los datos objeto de publicidad obligatoria son la escritura de constitución, la modificación de la escritura, la modificación de estatutos, el nombramiento, cese e identidad sujetos del Consejo de administración, el importe del capital suscrito en caso de delegación de aumento de capital, los documentos contables, el cambio de domicilio social, el nombramiento e identidad de liquidadores y sus poderes, el cierre de la liquidación, y la cancelación del registro en los Estados miembros en que ésta produzca efectos jurídicos.

Esta Directiva modificada prevé que los documentos puedan presentarse en formato papel o en soporte electrónico, a voluntad del interesado, y ello sin perjuicio de que los Estados puedan imponer a las sociedades la obligación de hacerlo exclusivamente por medios electrónicos.

Según la Directiva, todos los documentos que se presentaran a partir del 1 de enero, ya fuera en papel o en soporte electrónico, se debían incluir en la hoja registral correspondiente en formato electrónico. Además, impuso la obligación de garantizar que todos los documentos presentados en soporte papel se convirtieran en el Registro Mercantil en formato electrónico. Para aquellos documentos presentados antes del 31 de diciembre de 2006 no existía obligación de convertirlos automáticamente en formato electrónico, a no ser que se presentara una solicitud de publicidad por medios electrónicos. A partir del 1 de enero de 2007, las copias deben obtenerse del registro en papel o en formato electrónico, a elección del solicitante, con independencia de si los actos e indicaciones han sido archivados antes o después del 1 de enero de 2007.

Según la Modificación de Primera Directiva, el precio de la obtención de una copia de todos o de parte de los actos e indicaciones inscritos, ya 
sea en papel o en formato electrónico, no podrá ser superior al coste administrativo correspondiente. Las copias entregadas en papel serán certificadas de "conformes», mientras que las recibidas en formato electrónico no serán certificadas como "conformes» a menos que lo pida expresamente el solicitante. Los Estados miembros se asegurarán que la certificación de las copias electrónicas garantice la autenticidad de su origen y la integridad de su contenido, mediante una firma electrónica reconocida.

El Registro Mercantil español basa su procedimiento en lo impuesto por la Directiva 58/2003, en la que se regula un proceso de gestión electrónico, que permite la interoperabilidad entre los diferentes Registros Mercantiles, lo cual se ha visto afianzado con la incorporación del lenguaje XML y XBRL al desarrollo de estándares, estructuras de datos que permiten su integración en el Registro de manera sencilla. En la actualidad, se sustituyen los asientos en soporte papel por Asientos Registrales Electrónicos, cuyo almacenamiento constituirá la Hoja Registral Electrónica, única para cada sociedad. Para dotar de seguridad a los mismos, junto al estándar XML, se utiliza la firma electrónica reconocida de los Registradores.

Cuando se procede a formalizar los asientos de presentación, inscripciones, anotaciones, cancelaciones, archivos anejos y asociados, notas de calificación o despacho... se firmarán electrónicamente por el Registrador, convirtiéndose entonces en Asientos Registrales Electrónicos. También el Registro electrónico dará lugar a un documento electrónico registral que incorporará un código seguro de verificación, vinculado en un registro específico. De manera que se podrá comprobar, en cualquier momento la integridad del mismo accediendo a la sede electrónica correspondiente.

El Registro Mercantil deberá dar publicidad de diferentes actos de las sociedades mercantiles, en particular, deberá informar sobre la modificación de estatutos. Ésta, deberá inscribirse en el Registro y el Registrador la remitirá de oficio, de forma telemática, sin coste adicional alguno, al Registro Mercantil Central para su publicación en el Boletín Oficial del Registro Mercantil (BORM). También la inscripción del acuerdo de reducción de capital social se deberá inscribir en el Registro Mercantil, se deberá difundir a través de la plataforma del BORM y en la Web de la sociedad en caso de que existiera, para lo cual será suficiente, la declaración del Administrador indicando que estaba convocada a través de la web, sin que tenga de adjuntar ningún tipo de documentación que acredite la veracidad de su declaración. Estatutariamente se podrá indicar, en la SRL, que ningún acuerdo de reducción del capital que implique restitución de aportaciones, se pueda llevar a efecto sin que transcurran tres meses a contar desde la fecha de notificación. Esta notificación será personal. Si no fuera posible por desconocerse el domicilio de los acreedores, se realizarán anuncios en BORM y en la web social; o, si ésta no existe, en un diario de mayor circulación.

Con carácter general, y según lo dispuesto en el art. 35 de la LSC, "[u]na vez inscrita la sociedad en el Registro Mercantil, el registrador mercantil remitirá para su publicación, de forma telemática y sin coste adicional alguno, al Boletín Oficial del Registro Mercantil, los datos relativos a la escritura de constitución que reglamentariamente se determinen" siendo aplicable para todo tipo de actos que deban ser inscritos en el Registro Mercantil y después publicados en la plataforma del BORM.

\section{Sede electrónica de la sociedad de capital}

El reconocimiento de la sede electrónica de la sociedad de capital a través de su página web, que defendemos desde la aprobación de la Ley 26/2003 de 17 de julio, por la que se modifican la Ley 24/1988, de 28 de julio, del Mercado de Valores, y el texto refundido de la Ley de Sociedades Anónimas, aprobado por el Real Decreto Legislativo 1564/1989, de 22 de diciembre, con el fin de reforzar la transparencia de las sociedades anónimas cotizadas, finalmente se ha recogido en la reforma de la Ley de Sociedades de Capital de 16 de marzo de 2012, por la que se modifica el artículo 11 y se introducen nuevos, el art. 11bis, el 11 ter y el 11quater (Vañó, 2004; 2007).

La web corporativa se equipara al domicilio social a los efectos ejercitar el derecho de información, sustituyendo el modelo de anuncio en diarios o de la comunicación individual a los socios. En el caso de las sociedades cotizadas, sigue siendo obligatoria su creación desde la promulgación de la Ley de Transparencia, aunque con algunos efectos divergentes respecto de lo que se pretendía, ya que no ha conseguido que los operadores económicos sean controlados por el mercado.

La creación de la web exige el simple acuerdo de la junta general de socios, que deberá ir incorporado como punto del orden del día, sin embargo, en este punto debemos hacer referencia a la Instrucción de la Dirección General de Registros y del Notariado de 18 de mayo de 2011, trata de clarificar lo dispuesto en el art. 173 de la LSC al efecto. En la versión corregida 
de la misma, publicada el 28 de mayo de 2011, y en relación con este precepto, señala que "

[e]n los casos en los que se optara por la publicación de la convocatoria de la junta general en la página web de la sociedad, en aplicación de lo previsto en el artículo 173 de la Ley de Sociedades de Capital, tras la reforma introducida por el Real Decreto-Ley 13/2010, la sociedad deberá o bien determinar la página web en los estatutos de la sociedad o bien notificar dicha página web al Registro Mercantil, mediante declaración de los administradores, para su constancia por nota al margen.

De acuerdo con la Instrucción de la Dirección General, las sociedades pueden optar, bien por modificar los estatutos sociales para integrarla en los mismos, de manera que se le daría el mismo tratamiento que al domicilio social, sede física, o bien notificar la existencia de la web al Registro Mercantil a través de la simple declaración de los administradores, para su constancia por nota al margen. La primera de las opciones, que se incorpore a los estatutos, sería la forma más adecuada de cumplir con la exigencia del art. 173 de la LSC, teniendo en cuenta que se daría mayor seguridad a socios y terceros, sobre el medio en que se va a convocar la Junta General. El único problema es que cualquier cambio posterior en la misma, implicará una modificación estatutaria con los consiguientes costes y procedimiento.

Si se optara por el segundo supuesto, que el administrador hiciera constar en nota al margen la existencia o creación de la página web, tampoco debería considerarse problemático, si entendemos que entra dentro de las facultades de gestión ordinaria de la sociedad. Sin embargo, la equiparación de sede electrónica a domicilio social, a pesar de que carecemos de regulación específica, debería reconducirse, para conferir seguridad jurídica, al régimen jurídico previsto para el domicilio social en la LSC. Lo que resulta muy criticable es la posibilidad conferida al administrador de modificar, según lo dispuesto en el art. 11bis LSC, la web corporativa, su traslado o su modificación. No es comprensible, ni debería permitirse, por seguridad jurídica; a no ser que sea limitada la facultad de disponer sobre la misma estatutariamente. Quizás se ha querido equiparar la modificación de web corporativa al traslado de domicilio social en el mismo término municipal, pero lo cierto es que los efectos de una u otra modificación son diferentes (Alonso Espinosa, 2012).

Por resolución de la DGRN, de 8 de julio de 2011 se ha admitido una cláusula estatutaria en la que literalmente se señalaba "[l]a convocatoria de la junta deberá hacerse [...] por cualquier procedimiento de comunicación, individual y escrita, que asegure la recepción del anuncio por todos los socios". El Registrador rechazó la inscripción "al no determinar cuál es el procedimiento concreto de convocatoria" al considerarlo que

[...] es contrario a lo dispuesto en el art. 173.2 de la Ley de Sociedades de Capital y 186 del Reglamento del Registro Mercantil, cuya correcta interpretación exige que en los estatutos se precise el concreto medio a través del cual se va a realizar la convocatoria de la junta en aras de la seguridad jurídica tanto de los socios como del administrador o liquidador que son los obligados a realizar la convocatoria, quedando en otro caso al arbitrio del administrador que podría escoger en cada caso la forma que más interese a la Sociedad y no la que sea de más fácil recepción por los socios.

\section{La Dirección General señala al respecto que}

[...] la Orden JUS/3185/2010, de 9 de diciembre, en desarrollo del Real Decreto-ley 13/2010, de 3 de diciembre, aprueba unos Estatutos tipo para las sociedades de responsabilidad limitada, que en nada coinciden con la interpretación sostenida por dicha Resolución. En el artículo 5 del modelo de Estatutos-tipo que figura como anexo de dicha Orden, después de señalar que la convocatoria de la junta se comunicará a los socios a través de procedimientos telemáticos, mediante el uso de firma electrónica, a continuación dice: «En caso de no ser posible se hará mediante cualquier otro procedimiento de comunicación, individual y escrito que asegure la recepción por todos los socios...». O sea, los Estatutos tipo recogidos en la Orden Ministerial tienen la misma redacción en este punto que la que figura en el artículo 16 de los estatutos de la escritura calificada negativamente por el registrador Mercantil. $Y$ si se tiene en cuenta que la Orden JUS/3185/2010, de 9 de diciembre, tiene un efecto normativo del que carecen la Resoluciones de la Dirección General de los Registros y del Notariado, habrá que entender que el criterio de ese Centro Directivo no puede ser mantenido en lo sucesivo y que la fórmula de redacción empleada en la escritura calificada se ajusta a la legalidad.

Pero en el supuesto en que las sociedades sean nuevas, se debería incorporar esta mención a los estatutos, junto con el domicilio social. Sin embargo, la sociedad no podría, como tal, registrar el nombre de dominio, por cuanto no puede operar, excepto por lo dispuesto en el art. 36 sobre la sociedad en formación. Cualquier de los administradores podría solicitar el dominio y el alojamiento de la web, para, una vez constituida, transmitir la titularidad a la citada sociedad. Dicha transmisión es un procedimiento muy simplificado, que se podría llevar a cabo al mismo tiempo que la constitución, una vez adquirida la personalidad jurídica con la inscripción en el Registro Mercantil, a través del agente registrador correspondiente. En cualquier caso, sea en estatutos, o sea en hoja abierta en el 
Registro Mercantil, podrá hacerse constar, se publicará en el Boletín Oficial del Registro Mercantil y deberá permanecer en la web durante los 30 días siguientes a contar desde la inserción del acuerdo. La publicidad en el Boletín Oficial será gratuita, y los efectos jurídicos de la inserción en la web contarán desde la publicación en el BORM. Estatutariamente se podría exigir también que, antes de que conste en el Registro Mercantil, se notifique individualmente a los socios.

Esta obligación de permanencia del anuncio de web en la propia web, plantea otros problemas técnicos que el legislador no ha resuelto todavía, pero serán las entidades prestadoras de servicios de certificación las que deberán desarrollar los mismos y dar soluciones. Aunque la nueva versión del art. 173 de la LSC sobre convocatoria de la Junta General en su apartado 3, dice que

[l]os estatutos podrán establecer mecanismos adicionales de publicidad a los previstos en la ley e imponer a la sociedad la gestión telemática de un sistema de alerta a los socios de los anuncios de convocatoria insertados en la web de la sociedad.

A saber, si estamos utilizando la web corporativa para publicitar determinados acuerdos, ¿quién nos ofrece la garantía de autenticidad, de seguridad, de acceso gratuito, de posibilidad de descarga e impresión? Según el texto modificado de la LSC es competencia de la sociedad, según dispone el art. 11ter. La carga de la prueba es competencia, igualmente, de la sociedad; y la obligación de mantener lo insertado en la web durante los plazos legales, así como la posible responsabilidad por interrupción temporal, les corresponderá a los administradores. Sin embargo, a efectos de inscripción registral, será suficiente la simple declaración de los administradores indicando que han cumplido con la legislación vigente. Lo que podrá desvirtuarse por cualquier interesado mediante prueba admisible en derecho. Pero entonces, la carga de la prueba y la dificultad de la misma, recaerá sobre socios y terceros, lo que resultará sumamente difícil, sobre todo si tenemos en cuenta la desigualdad en las posiciones que ocupan cada una de las partes. De hecho, desde la Sentencia del Tribunal Supremo de 10 de julio de 1943 inició como tendencia, que en la responsabilidad extracontractual rige el principio de inversión de la carga de la prueba, siendo el perjudicado el que deberá acreditar el daño, de manera que a partir de ahí resultarán los demás presupuestos de la responsabilidad del autor, salvo prueba en contra del demandado.

El art. 11ter de la LSC prevé el supuesto de interrupción del acceso superior a dos días con- secutivos o cuatro alternos, de manera que no podrá celebrarse la Junta General convocada para acordar sobre el asunto a que se refiera el documento inserto en esa página, salvo que el total de días de publicidad efectiva fuera igual o superior al legal. Pero nos encontramos con la misma pregunta que hemos formulado supra, ¿a quién le corresponde probar que ocurrió o qué no ocurrió este hecho? A la respuesta de la declaración de los administradores, que tendrán que desvirtuar los socios o terceros interesados, debemos oponernos, por el desequilibrio entre las distintas posiciones, por lo que el Legislador debería haber exigido la prueba documental o electrónica de cumplir con todos los requerimientos a los administradores o a la sociedad.

Por otra parte, el art. 11quáter modificado por la Ley $1 / 2012$, de 22 de junio (BOE del 23), además de solicitar que las comunicaciones electrónicas sean aceptadas por el socio, obliga a la sociedad a que habilite a través de la propia página web un dispositivo de contacto con la sociedad que permita acreditar la fecha indubitada de la recepción, así como el contenido de los mensajes intercambiados. Lo cual supone una mayor seguridad jurídica en la recepción del mensaje para el socio, y para la protección de su derecho de información.

\section{Interoperabilidad entre registros mercantiles}

La interoperabilidad de los Registros Mercantiles, impuesta por la Modificación de primera Directiva de Sociedades es importante no ya por su consideración de bases de datos interconectadas, cuyo acceso es público, sino porque pretendía ser un sistema de control de la gestión empresarial cuyos sujetos interesados no son sólo los Registros Mercantiles sino también la Comisión Nacional del Mercado de Valores, el Banco de España, la Agencia tributaria, socios e inversores, entre otros (Vañó, 2009).

La modificación de Primera Directiva sobre sociedades el 11 de junio de 2003, obliga a que incorporen una tecnología que permita el intercambio electrónico de información y que sea a la vez capaz de ofrecer seguridad a los usuarios de dicha información.

La interoperabilidad de los Registros Mercantiles y en particular entre Registros mercantiles europeos no puede entenderse sin la referencia explícita al proyecto CRXML, que posteriormente se convirtió en el proyecto EBR, European Business Register y más tarde ha confluido en el llamado Proyecto BRITE (Business Register Interoperability Throughout Europe). 
El Registro de Empresas Europeas (EBR) es una red de registros nacionales de empresas y proveedores de información en la Unión Europea. Con la creación de esta plataforma se busca facilitar el acceso a la información actualizada de las sociedades europeas, directamente desde el Registro oficial de cada país. Lo cual se incorporó a la Primera Directiva de Sociedades, en su modificación de 2003 y la posterior de 2009.

A través de EBR cualquier usuario podrá obtener información oficial de las sociedades pertenecientes a los países conectados a la red, a precios razonables, mejorando la situación de las pequeñas y medianas empresas, que hasta hace relativamente poco tiempo encontraban dificultades para acceder a información de otras empresas europeas ( www.ebr.org).

Esta plataforma es parte del proyecto BRITE, cuyos objetivos son principalmente fijar los parámetros técnicos de la interoperabilidad, a saber:

- Establecer un marco que permita la interoperabilidad de los Registros mercantiles en Europa.

- Transformar y armonizar procesos administrativos aislados en acciones cooperativas y coordinadas.

- Añadir transparencia a varios perfiles de negocio, y mejorar el acceso público a los documentos archivados.

- Eliminar barreras administrativas con el fin de consolidad la libertad de establecimiento y libertad de movimiento de las sociedades.

- Buscar el desarrollo y la adopción de sistemas de soporte que adaptable y proactivos en el e-Government.

- Avanzar en el estado del arte de los procesos de diseño de los procesos administrativos utilizando ontologías y web semántica.

Los servicios que pueden desarrollarse a través del Proyecto BRITE son la búsqueda de información sobre determinadas sociedades y el acceso a diferentes tipos de informes disponibles, dependiendo del país y del tipo de sociedad. En noviembre de 2011 se puso en marcha la versión 3.0 de EBR, la nueva plataforma que trata de mejorar la interconexión de las bases de datos, incorporando mejoras relacionales.

EBR ofrece la información de la empresa sobre la cual buscamos información, basándose en el art. 2 de la Primera Directiva de Sociedades, en concreto datos como la denominación social, número de registro, dirección, país de registro, fecha de registro, autoridad registradora, forma legal, estatus, objeto social, capital social, y fecha de las últimas cuentas anuales depositadas.

Esta plataforma se configura como Directorio de registros, con un índice central de nombres que facilita búsquedas mucho más sencillas. No es un Registro central europeo de sociedades, ya que los registros nacionales mantendrán su primacía.

Además, usando el estándar XML —que estandariza y etiqueta el contenido permitiendo la traducción de los términos y conceptos usados- el intercambio de mensajes se realiza con un alto nivel de seguridad.

Concretamente, la se regula en la Resolución legislativa del Parlamento Europeo, de 14 de febrero de 2012, sobre la propuesta de Directiva del Parlamento Europeo y del Consejo por la que se modifican las Directivas 89/666/CEE, 2005/56/CE y 2009/101/CE en lo que respecta a la interconexión de los registros centrales, mercantiles y de sociedades - COM (2011)0079 C7-0059/2011 - 2011/0038(COD)— de 14 de febrero de 2012.

La interconexión de los registros centrales, mercantiles y de sociedades, según describe la propuesta de Directiva, exige la coordinación de sistemas nacionales con diferentes características técnicas; por lo que se deberán adoptar medidas y especificaciones técnicas que deberán tener en cuenta las diferencias entre los Registros nacionales. Con el fin de garantizar unas condiciones uniformes para la aplicación de la Directiva, se conferirán a la Comisión competencias de ejecución para abordar estos problemas técnicos y operativos de acuerdo con lo dispuesto en el Reglamento de la Unión Europea $n^{0} 182 / 2011$.

Las líneas directrices de la Propuesta de modificación de las Directivas 89/666/CEE, 2005/56 y 2009/101/CE pretenden garantizar que las sucursales, al igual que cualquier empresa, tengan un código identificativo europeo único. Los Registros mercantiles se transmitirán entre sí notificaciones electrónicas en los procedimientos transfronterizos de fusión (la Comisión regulará las especificaciones técnicas). Se pretende garantizar que los actos e indicaciones contenidos en los Registros mercantiles de los Estados miembros estén siempre actualizados. Deberán actualizarse en los 15 días siguientes al cambio. Se procurará un código para la identificación de todas las sociedades de capital europeas lo que facilitará su identificación. Se fortalecerá el acceso transfronterizo a la información recogida en el art. 2 de la Primera Directiva de Socieda- 
des a través de la creación de la plataforma electrónica europea única con servicio web central, facilitando la interoperabilidad de Registros $\mathrm{y}$, por tanto, implantar una red electrónica urgencia que ya destacó Fernández del Pozo (2003).

Los Estados miembros facilitarán la información exigida para la publicación en el Portal Europeo de e-Justicia ("el portal") de conformidad con las normas y requisitos técnicos del Portal. Se establecerá una plataforma central europea ("la plataforma").

El sistema de interconexión de los registros centrales, mercantiles y de sociedades constará de los registros de los Estados miembros, la plataforma y el portal como punto de acceso electrónico europeo.

En esta norma se incorpora el Green Paper para la interconexión de Registros Mercantiles de 4 de noviembre de 2009 así como los comentarios realizados al mismo en abril de 2010 . Los principios en los que se basaba eran el acceso a la información y el de cooperación entre Registros mercantiles, basados en EBR.org, y utilizando otras herramientas e iniciativas como el Sistema de información del mercado interior (IMI) y el e-Justice. En las propuestas formuladas por los distintos operadores económicos, se propuso la utilización de XBRL, que se ha recogido como estándar básico de interoperabilidad, junto con XML. Se propuso que existiera una mayor homogeneidad en los datos inscritos, que las modificaciones de los datos del Registro se actualizaran frecuentemente y que se incorporaran a una base de datos central sobre cargos revocados, que no ha sido incorporada de manera específica en la Resolución de Directiva y el acceso gratuito a la información registral interregistros.

El 16 de junio de 2012 se aprobó la Directiva 2012/17/UE relativa a la interconexión de los registros centrales, mercantiles y de sociedades. En su texto se recogen las propuestas formuladas por el Green Paper, y con ella se pretende dar una mayor difusión y publicidad de las operaciones de modificación estructural intracomunitarias, publicidad de sucursales, y además, favorecer la competitividad de las empresas al reducir las cargas administrativas e incrementar la seguridad jurídica.

La plataforma, según indica la Directiva, deberá consistir en un conjunto centralizado de servicios que integren herramientas informáticas con una interfaz común para el portal, que será considerado como punto de acceso electrónico europeo a través del lenguaje XML. Será una plataforma de interconexión; en ningún caso será una entidad independiente y con personalidad jurídica.

No se pretende armonizar los registros centrales, sino crear un punto de información etiquetada en los diferentes idiomas, y a la que deberá poder acceder cualquier usuario.

Los Estados miembros velarán por que la información sea actualizada en un plazo de ventiún días a partir de la recepción de la documentación completa, a diferencia de los quince días que se proponía en el Green paper.

Si la plataforma fuera gestionada por un tercero, deberá garantizarse la continuidad de la prestación de servicios por parte del sistema de interconexión de registros con la correspondiente supervisión pública del funcionamiento de la plataforma.

No se ha incorporado la propuesta de acceso gratuito que se demandaba por la sociedad y que se refirió en el Green Paper. De hecho, la Directiva admite la posibilidad de fijar tasas, si el Estado ya las había fijado.

\section{Conclusiones}

La publicidad llevada a cabo a través del Registro Mercantil y Boletín Oficial del Registro Mercantil, promovida por la primera Directiva de Sociedades y que ha sufrido numerosas modificaciones desde que se aprobó en 1968, ha ido incorporando progresivamente menciones a la necesidad de incrementar la transparencia. En 2002, con el informe Winter, se desarrolló la transparencia en las sociedades mercantiles con el fin de que los socios pudieran ejercer sus derechos y pudieran interactuar con la sociedad a través de las tecnologías de la información y la comunicación.

En España, la promulgación de la Ley de Transparencia de las sociedades cotizadas, y la propia evolución del Registro Mercantil, ha propiciado su plena informatización y su incorporación al objetivo de lograr la plena transparencia en el mercado, que, sin embargo, no se podrá conseguir totalmente si no se logra un acceso gratuito a dicha información. En su política de recaudación, es criticable que no solo cobran las tasas por depositar la documentación tal y como lo establece la Ley, sino que además cobran por consultar. Lo cual supone una gran barrera para el acceso a toda la documentación, y choca con la consideración de público del Registro Mercantil español.

La informatización requería la estructuración de bases de datos, que utilizaban primero el soporte papel y luego el soporte informático, lo que 
era imposible, si no se conseguía que la estructuración de la información se hiciera en base a un mismo etiquetado de datos.

Por ello, se utilizó desde 1999 la estructura de datos XML, que permite una interoperabilidad absoluta entre bases de datos que hablan un mismo lenguaje. Su extensión desde España, Holanda e Italia a los órganos de la Unión Europea ha dado origen a la plataforma de interconexión entre Registros europeos, mercantiles y de sociedades, así como la creación de una plataforma de contratación con el sector público.

\section{Referencias}

Alonso Espinosa, Francisco José (2012). Telemática y derecho de sociedades. // Diario la Ley. 7800 (17 febrero de 2012).

Del Valle Hernández, Ana María (2008). El Registro Mercantil Electrónico. // Revista Aranzadi de Derecho y Nuevas Tecnologías. 18, 19-33.

Farias Batlle, Mercedes (1998). Realidad del tráfico y Registro Mercantil (algunas reflexiones sobre el principio de inoponibilidad). // Revista Critica de Derecho Inmobiliario. $646,903-930$

Fernández del Pozo, Luís (1990). El nuevo Registro mercantil, sujeto y función mercantil registral: crítica sobre su ámbito internacional. Madrid: Colegio de Registradores de la Propiedad y Mercantiles de España, 1990.

Fernández del Pozo, Luís (2003). El derecho internacional del registro mercantil y la publicidad registral de la sociedad europea (societas europea). // Revista de Derecho Mercantil. 248 (abr. jun. 2003) 499-554.

García Villaverde, Rafael (1990), La reforma del Registro Mercantil // Diario la Ley. 2 (19 de junio de 1990) 11801197.

Vañó Vañó, María José (2004). Información y gobierno electrónico en las sociedades cotizadas. // Revista de Derecho Bancario y Bursátil. 95 (septiembre de 2004) 77-122.

Vañó Vañó, María José (2007). Medios telemáticos y derecho de representación. // Revista de la Contratación Electrónica. 82 (mayo de 2007) 3-35.

Vañó Vañó, María José (2009). Integración de la documentación legal electrónica a través de LEXML. // Scire: Representación y Organización del Conocimiento. 15:1 (ene.-jun. 2009) 87-110.

Vicent Chuliá, Francisco; Fernández Del Pozo, Luís (2000). Internet y Derecho de sociedades. Una primera aproximación. // Revista de Derecho Mercantil. 237 (jul.-sept. 2000) 915-1002.

Enviado: 2012-05-30. Versión corregida: 2012-08-02. Aceptado: 2012-08-11. 
